\title{
Aeromagnetic and remote sensing interpretation and prospecting prediction of Xinjiang Pobei area
}

\author{
Li Yan ${ }^{1,2, a}$, Wang Chenyang ${ }^{1,2,3, b}$, Zou Weilei ${ }^{1, c}$ and Yang Rihong ${ }^{1,2, d}$ \\ 1.China Aero Geophysical Survey and Remote Sensing Center for Land and Resources, Beijing \\ 100083 China \\ 2 Key laboratory of airborne geophysics and remote sensing geology, Ministry of land and \\ resources, Beijing 100083 \\ 3.China University of Geosciences(Beijing), Beijing 100083 China \\ a408375970@qq.com, bagrswcy@163.com, czouweilei@agrs.cn, dyangrihong@sina.com
}

\section{Keywords: Pobei aeromagnetic alteration extraction metallogenic prediction}

\begin{abstract}
Pobei area is one of the important copper-nickel mineralization prospect area of Xinjiang. In this paper, we process and analyse the 1:50,000 high-precision aeromagnetic data of the Pobei area, and extract alteration information of remote sensing, combining the metallogenic geological conditions of the study area and known mineral information, we analyse the regional structure, rock aeromagnetic and remote sensing anomalies comprehensively. Based on the features of aeromagnetic and remote sensing anomalies, we point out that area A3 and A4 rich in anomaly information and with good mineralization prospects, which can be used as clues for further exploration. The combining use of aeromagnetic and remote sensing methods has unique advantages for inferring geological characteristics of rock, tectonic interpretation and mineralization forecast. The two methods are combined to make up the shortcomings of the conventional single source of information, and reduce the multiplicity of geological interpretation.
\end{abstract}

Foundation: Youth Innovation Fund Program of AGRS(NO.2013YFL14)

\section{Introduction}

Aeromagnetic measurement is based on the magnetic differences between rocks (minerals) under the ground, by measuring the magnetic signatures of geological body, then study the geological structure and distribution of mineral resources. It has the advantages of great detection depth [1]. The remote sensing technology focus on detecting surface radiation and geometric information, it's concerned with the geometrical and physical properties of the surface. Although the principle of the two methods are different, they all describe the properties and characteristics of observed geological body by detecting field information. There is a natural complementarity between the two methods.

Aeromagnetic survey and remote sensing geological prospecting techniques are non-contact exploration method, which are particularly suitable for field geological survey under difficult conditions in western China[2-3]. Pobei locate in northeast margin of the Tarim plate, Beishan area, east of Lop Nor, XinJiang. In recent years, large $\mathrm{Cu}-\mathrm{Ni}$ sulfide deposits were discovered in this area, which make the area becoming the important exploration targets. But most part of the area are uninhabited, it's very hard to deploy the conventional field geological survey[4-5] , so it has practical significance for using aeromagnetic geological survey and remote sensing technology to carry out prospecting application research in this area.

In this paper, we used 1: 50,000 high precision aeromagnetic data of southeast edge of East Tianshan, Xinjiang. The original data after pretreatment and potential field conversion, then combined with the geology-mineral resources information, and using with remote sensing technique, we can comprehensive analysis of Pobei-rock mass aeromagnetic and remote sensing anomaly characteristics. For this A3 and A4 can be found abnormal information-rich and good prospects for mineralization, these can be used as a further prospecting clues. Aeromagnetic and Remote Sensing methods complement each other, greatly improving the reliability of interpretation. 


\section{Geology and mineral overview of research area}

Pobei locate in the east of Lop Nur Xinjiang, and in the western part of the northern rift zone which is the second level tectonic unit of Tarim continental crust, and in the south of regional Baiwadi deep fault. The Pobei rock mass is mainly composed of a dozen intrusive bodies, including Po1, Po3, Po7 and Po10 etc. It is obviously controlled by regional faults and present NE-SW distribution.

The strata are mainly Lower Proterozoic North hill group, the Middle Proterozoic Changcheng System White lakes group and Paleozoic Lower Carboniferous Hongliuyuan group, Middle Carboniferous Shiban hill group and Quaternary(Fig.1).

The region experienced a number of tectonic movements, folds and faults are well developed. Folds are mainly regional closely linear style. The main structure is regional Baiwadi deep fault which controls the stratum, tectonic and magmatic rock distribution of the area. The late Variscan mafic-ultramafic intrusive rocks are most widely spread outcropping intrusive rocks in the area, followed by acid rock.

The Po one rock mass of Pobei have proven industrial resource of 548,100 tons of nickel, 212,500 tons of copper, 57,500 tons of cobalt; Po ten rock mass have proven industrial resource of 23,000 tons of nickel, 13,000 tons of copper, 6,000 tons of cobalt[6]. Ore body are mostly bedded and lenticular which occurs in the lower part of the rock, the main ore-bearing rock is augite peridotite and peridotite. The main ore types are sparse disseminated. Penetration style bonanza occur locally.

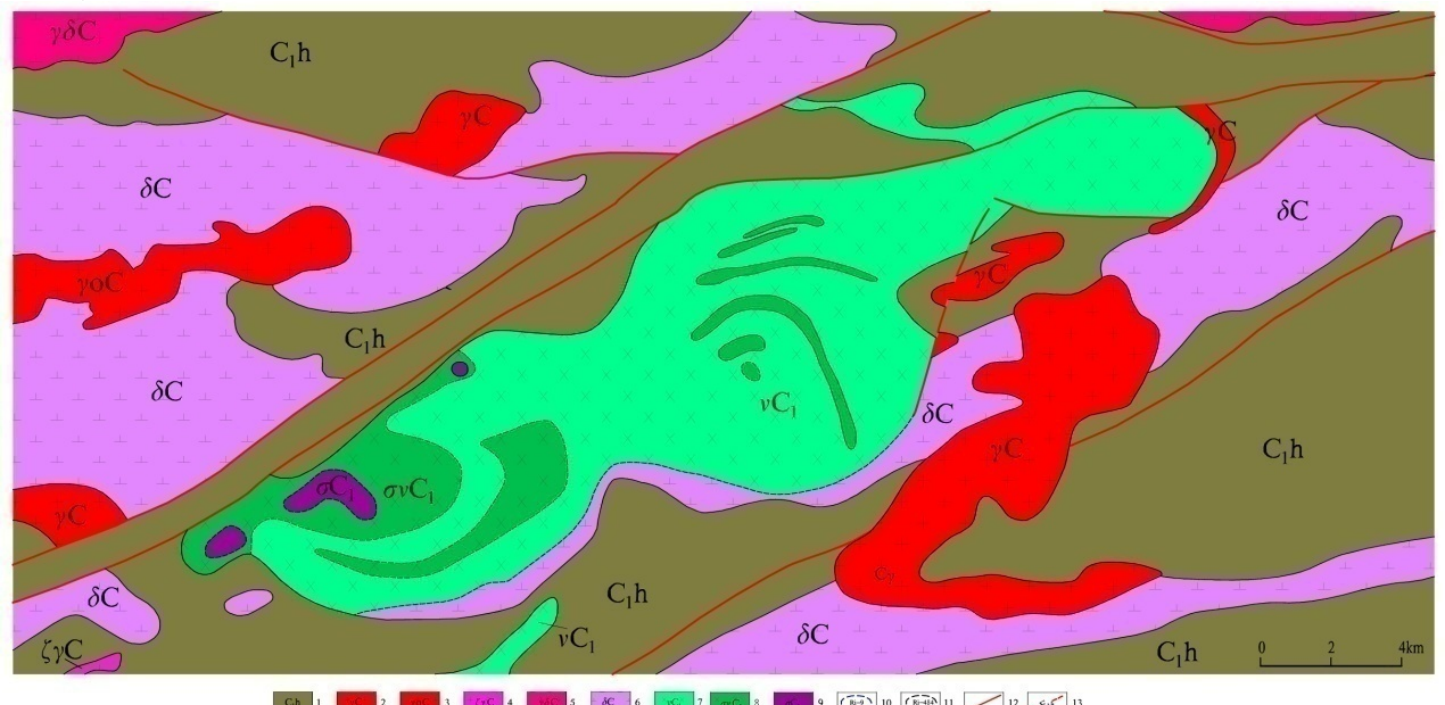

Figure 1 Geology map of Pobei area

1- Lower Carboniferous red group 2- Carboniferous granite 3- Carboniferous plagiogranite 4Carboniferous moyite 5- Carboniferous granodiorite 6- Carboniferous diorite 7- Carboniferous gabbro 8- Early Carboniferous olive gabbro 9- Early Carboniferous peridotite; 10- Aeromagnetic infered Beipo rock boundary and rock number 11- Olive gabbro, gabbro boundary and rock number 12- Geological fracture; 13- Infered fracture and number

\section{Data acquisition and processing}

3.1 The original aeromagnetic data acquisition and processing

Aeromagnetic measurement scale is $1: 50,000$, the survey line spacing is $0.5 \mathrm{~km}$, direction is $0^{\circ}-180^{\circ}$, which is perpendicular to the main geological structure of the survey area substantially. The control line spacing is $10 \mathrm{~km}$, direction is $90^{\circ}-270^{\circ}$, the overall form the measuring network of $0.5 \mathrm{~km} \times 10 \mathrm{~km}$. The results of actual measurements show that the magnetic information is rich, details are complete and clear, and the regularity of magnetic field spatial distribution is obvious, indicating the designed measuring network layout is reasonable, the desired measurement results achieved.

The original aeromagnetic data are processed through synchronization correction, normal field 
correction, magnetic field diurnal variation correction and leveling. The statistics show that the average fly altitude of survey area is $146 \mathrm{~m}$, and the total accuracy of aeromagnetic measurment is \pm $0.92 \mathrm{nT}$, which meet the aeromagnetic measure quality specifications.

We use the GeoProbe 2.0 and Mapgis software for data processing and preparation of maps. The basic data processing include reducing to the pole, upward continuation, and the first order vertical derivative.

3.2 Remote sensing data acquisition and hydroxy mineral anomaly extraction

In this study,we use US landsat 8 data, track number is 139/32, imaging date is March 12th, 2014. The remote sensing image quality is good, with less interference information, image is clear, and rich in geological information. In data prosessing, we did radiometric calibration, atmospheric correction, projection registration and fusion to the images, after numerous tests, we select 753 false-color image synthesis scheme.

The main alteration information extraction methods are band ratio method, principal component analysis method and spectral angle mapping method. Results of band ratio method often contain a large number of false anomalies, and spectral angle method mainly used for hyperspectral remote sensing data. Principal component analysis method is mature, with a wide range of validity and applicability. In this study, we use this method. Principal component analysis refers to under the premise of total amount of information unchanged, removing the correlation between the characteristics bands by multi-dimensional orthogonal linear transformation, and there is no duplication or redundancy between the resulting principal component information, the feature matrix of each band's contribution coefficient symbols can be used to determine the most appropriate principal component image for extracting alteration information.

Referring to the previous use of Landsat7 remote sensing data anomaly extraction method[7-9]. We did masked principal component analysis to pretreated Landsat 8 1,5,6,7-band data. The main components output dynamic range was set as $\pm 4 \sigma$ (standard deviation) to obtain the main components of remote sensing hydroxyl alteration anomalies.

Table 1 Landsat 8 satellite band 1,5,6,7 data principal component analysis eigenvectors matrix

\begin{tabular}{c|c|c|c|c}
\hline \hline \multirow{2}{*}{$\begin{array}{c}\text { Principal } \\
\text { component }\end{array}$} & \multicolumn{4}{|c}{ Band } \\
\cline { 2 - 5 } & Band1 & Band5 & Band6 & Band7 \\
\hline PC1 & -0.23163812 & -0.52956357 & -0.61066727 & -0.54128708 \\
\hline PC2 & -0.48558051 & -0.60022334 & 0.15932985 & 0.61527027 \\
\hline PC3 & -0.80770169 & 0.37248035 & 0.29372834 & -0.35014286 \\
\hline PC4 & -0.24119147 & 0.46963045 & -0.71792976 & 0.45370781 \\
\hline \hline
\end{tabular}

As can be seen from the eigenvector matrix, eigenvector of band7 and band 5 have opposite sign from eigenvector of band 6 in PC4, so PC4 is determined as main component of anomaly. and then as The mean value and standard deviation of pixel gray value $(\sigma)$ were calculated based on principal component, and the $1.5 \sigma, 2.0 \sigma$ and $2.5 \sigma$ were established as threshold to extracte level 1,level 2 and level 3 hydroxyl mineral anomalies. The anomalies were superimposed on synthesized image of band 7 (R) 5 (G) 3 (B) to form the hydroxyl mineral anomaly distribution image of the study area (Figure 2). 


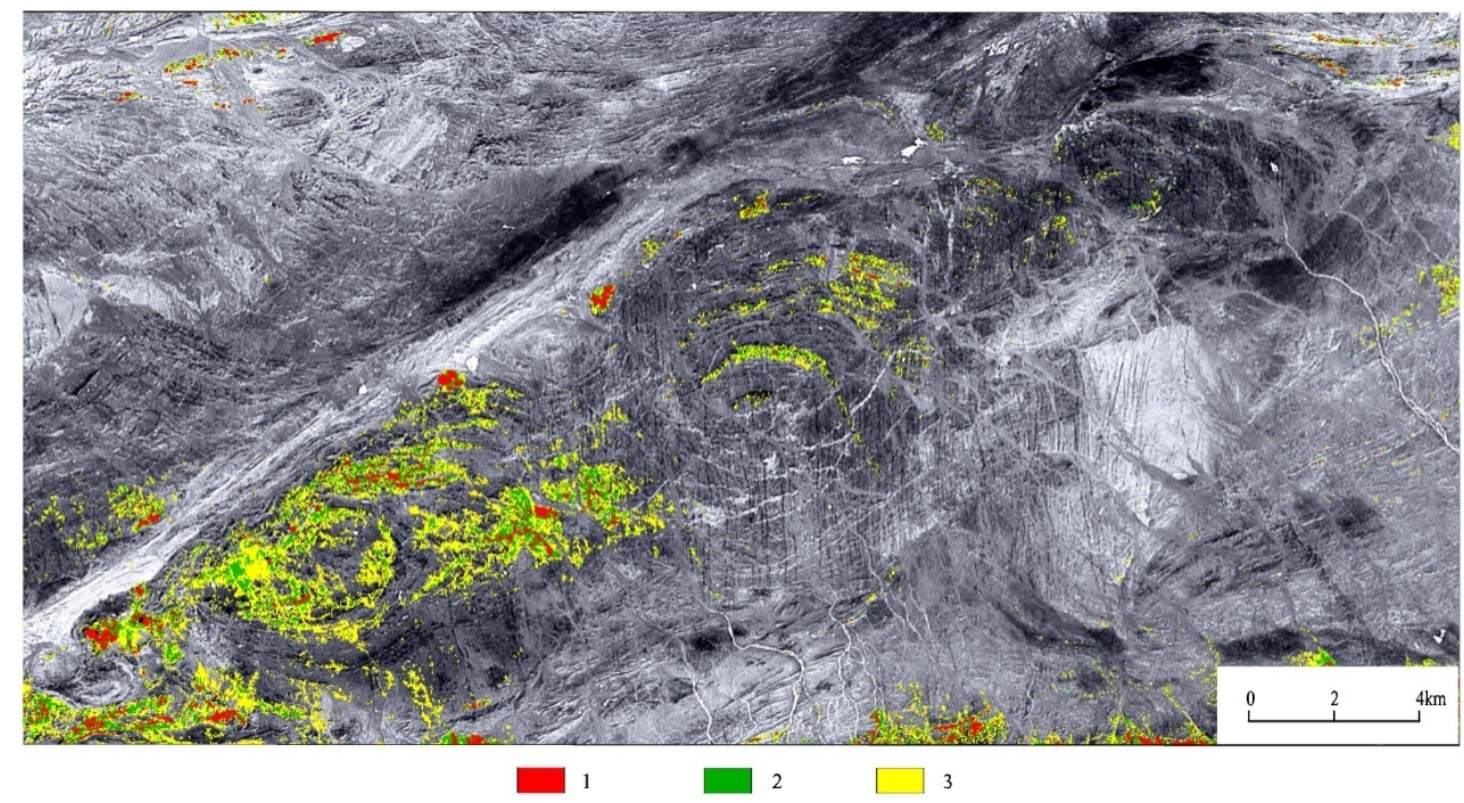

Figure 2 Hydroxyl mineral anomaly distribution image

1 Level 1 hydroxyl mineral anomaly 2 Level 2 hydroxyl mineral anomaly 3 Level 3 hydroxyl mineral anomaly

\section{Features and geological interpretation of Pobei rock mass}

\subsection{Aeromagnetic features of rock mass}

Aeromagnetic interpretation shows that the output and pattern of Pobei rock mass is controlled strictly by a major fault and its secondary fault structures. Rock mass is NE trend, and distribute along NE trending fault F14 which break through and control the intrusion and formation of Pobei rock mass. The NEE trending fault F54 break through the west part of rock mass, and intersect with fault F14 in the middle of Pobei rock mass (Figure 3).

In aeromagnetic $\Delta \mathrm{T}$ flat profiles, the rock mass correspond to the $\mathrm{NE}$ trending strong spike-shaped negative magnetic anomaly zone, and weak spike-like positive magnetic anomaly was superimposed internally (Fig. 4). Morphology of magnetic anomaly show that the lithology varies inside the rock mass, and magnetic properties of different rocks have great difference. In a number of lines, abnormal curves are sharp and steep, with symmetrical wings mostly.

In aeromagnetic $\Delta \mathrm{T}$ contour plan (Fig. 5) and aeromagnetic $\Delta \mathrm{T}$ contour plan of the pole (Fig. 6), the magnetic anomalies of rock mass are similar, which are the NE tilted flasks like negative magnetic anomaly area, wide slow small positive magnetic anomalies superimposed internally. Flask shaped negative magnetic anomaly area distribut along the NE trending fracture F14, superimposed small positive magnetic anomaly area is basically distribut along NEE trending F54 fracture, which indicating the different parts intrusive rocks were subject to different fractures. Anomaly area have multiple low centers. Overall, the anomaly area have clear boundaries with the background field, the boundaries between the internal small positive anomalies and negative anomalies are generally less obvious.

In reference the 1:200000 and 1:25 000 geological maps (Figure 1), the anomaly area are consistent with the Pobei rock mass, which should be the effect of Carboniferous olive gabbro gabbro rock in the magnetic field. The negative magnetic field region are consistent with Carboniferous gabbro rock body, the internal superimposed positive anomalies are consistent with the Carboniferous peridotite-olive gabbro rock body basically. 


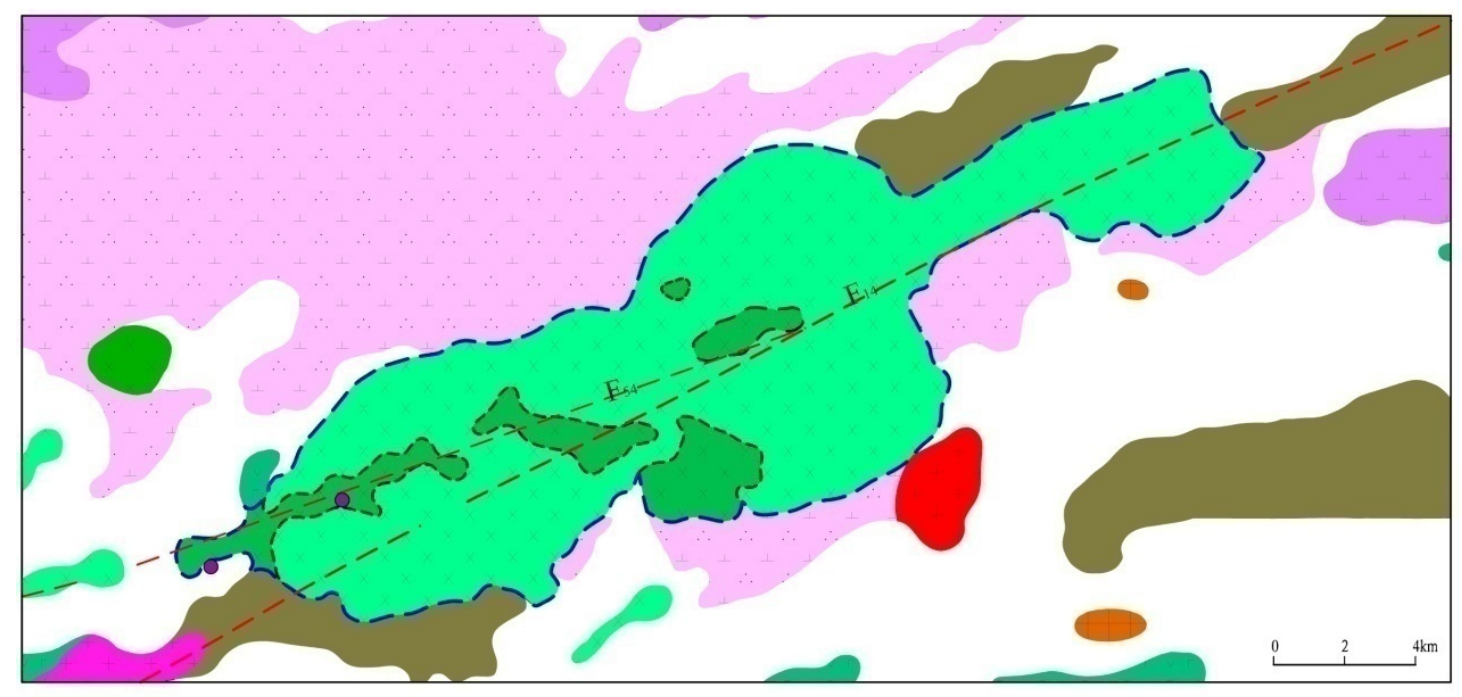

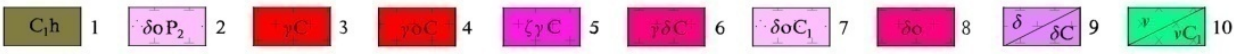

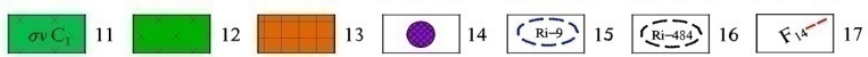

Figure 3 Pobei area faults geological interpretation map

1- Lower Carboniferous Hongliuyuan group; 2- Middle Permian Carboniferous diorite; 3Carboniferous granite; 4- Carboniferous plagiogranite; 5- Carboniferous moyite; 6- Carboniferous granodiorite rock; 7- Carboniferous quartz diorite; 8- undivided quartz diorite; 9- diorite / Carboniferous diorite; 10- gabbro / early Carboniferous gabbro; 11- early Carboniferous olive gabbro; 12- diabase mafic intrusive rocks; 13- infer altered rock; 14- nickel; 15- aeromagnetic inferred Pobei rock mass boundary and rock numbers; 16- aeromagnetic inferred Olive gabbro and gabbro rock boundaries and numbers; 17 - inferred fracture and numbers

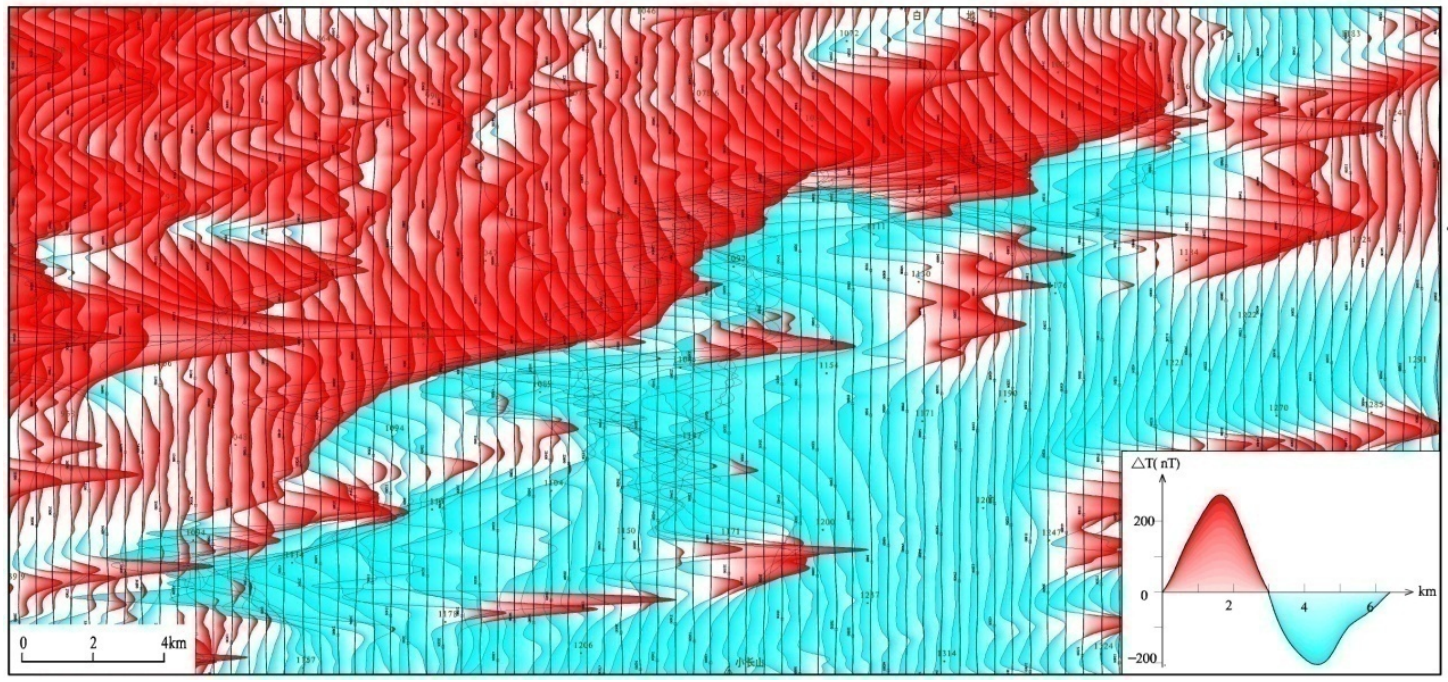

Figure 4 Aeromagnetic plane map 

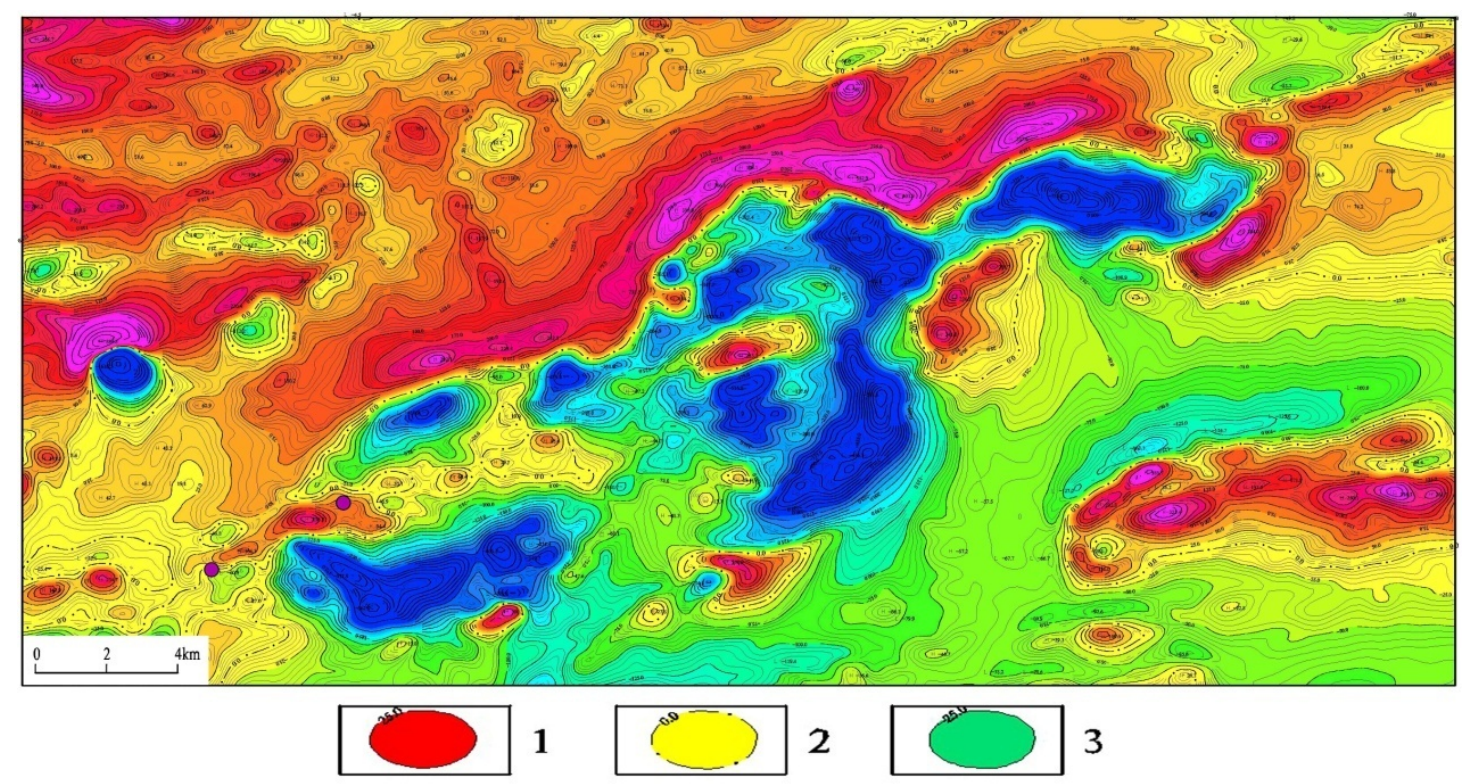

Figure 5 Original aeromagnetic contour map
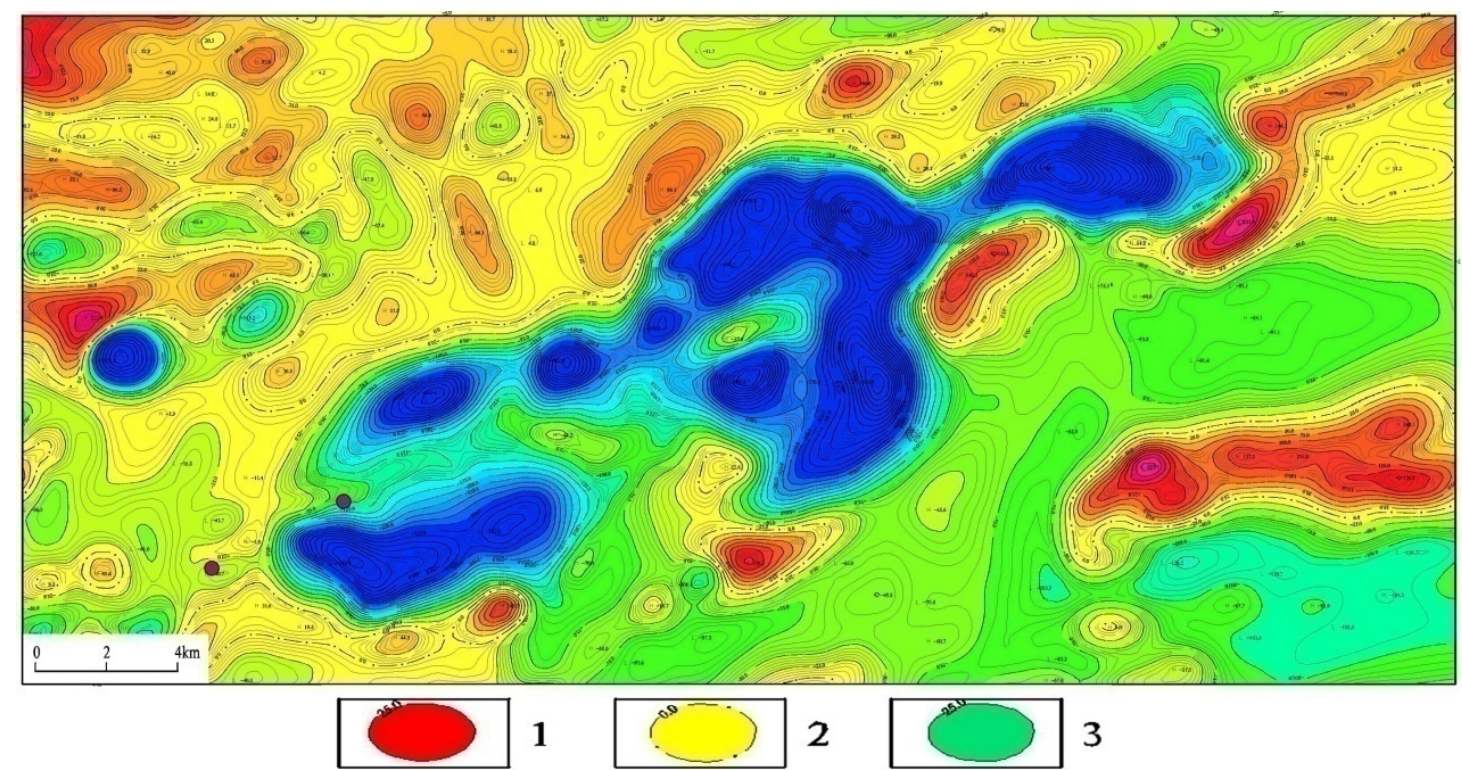

Figure 6 Aeromagnetic of the pole contour plan map

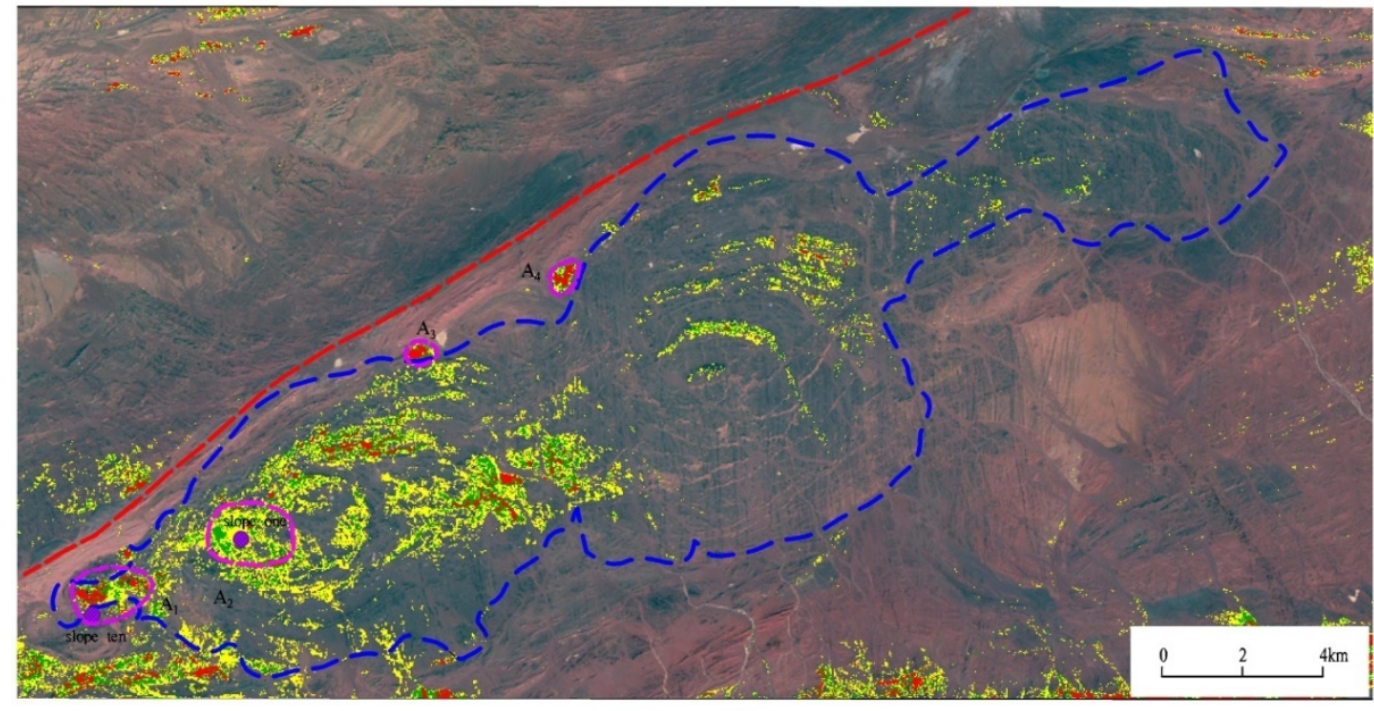

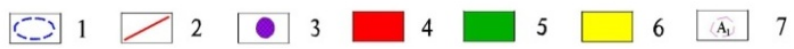

Figure 7 Aeromagnetic and remote sensing interpretation map for prospecting forcast 
1- aeromagnetic inferred Pobei roch mass boundary; 2- remote sensing inferred fracture; 3- known mine sites; 4- level one hydroxy a mineral anomalies; 5- level two hydroxy mineral anomalies; 6level three hydroxy mineral anomalies; 7- remote sensing predicted prospecting zone and number

4.2 Remote sensing feature of the rock mass

By applying image enhancement, image conversion and image analysis methods to enhance the tone, color and texture difference, we get the Pobei remote sensing image, this image is colorful, the boundary of Pobei rock mass is clear and intuitive. As can be seen from the image, the tilted flask shaped Pobei rock mass distribute along NE direction, and its texture have beaded patterns, the color is dark and gray. The boundary of Pobei rock mass in the remote sensing image is consistent with aeromagnetic inferred Pobei rock mass boundary basicly. (Fig. 7).

\section{Prospecting forecasting}

\subsection{Remote sensing alteration information optimization}

The purpose of researching remote sensing alteration information is to indicate favorable metallogenic area, but information extracted from remote sensing alteration and mineralization are not all related, so it need to optimize the extraction results。Alteration information optimization has to consider the geological conditions of the study area, Such as surrounding rock and fracture structure, etc. Only within the scope of the metallogenic geological background selection of alteration information can indicate the possibility of mineral 。Comprehensive analysis, the study area selected $A_{1}, A_{2}, A_{3}, A_{4}$ hydroxy mineral alteration anomalies to be analyzed.

\subsection{Prospecting Potential Predictive Analysis}

Comprehensive analysis of remote sensing region hydroxy mineral anomaly distribution A1, A2, and compared with the known aeromagnetic interpretation, geology and mineral resources information, We found that Area $A_{1}, A_{2}$ are very consistent with Po one and Po ten Mining which have been found (Figure7). This again confirms the remote sensing alteration information extraction can offer important instructions for prospecting.

In the study area , mineralization geological studies indicate that the rock mass of Pobei is mainly about nickel, iron magmatic segregation - penetration type mineralization, mineralization is closely related magmatic rocks. On the other hand, Po one, Po ten which are the size of the ore bodies are distributed along the faults, metallogenic regularity evident. it indicates that magmatic hydrothermal migration is upward along with the weak structure and precipitation, enriched mineralization, fracture has played an important role for lead mines and ore-hosting structures in the mineralization. Magmatic fluid along the fracture rise to rock contact zone i.e ore-gathering sites then ore-forming, so rock contact zone is the most promising exploration areas.

Aeromagnetic and remote sensing geological interpretation (Figure 7) shows that the northern margin of Pobei near the north-trending faults, area A3 and A4 is near the intersection of fracture and rock edge, rock and fracture edges belong to tectonic weak location, they are the good channels for deep magmatic hydrothermal ore upward migration. Cataclastic rocks inside of fracture and rock edge provide ample space and transformation conditions for precipitation and enrichment of ore-forming materials. Therefore, area A3 and area A4 has very favorable metallogenic geological structure. On aeromagnetic $\triangle T$ profile plan, A3 and A4 showed positive anomalies background field-relief multimodal abnormal, the maximum intensity is 250nT. On aeromagnetic $\triangle T$ contour plan, A3 and A4 is located in a strip positive anomalies mayor exception, which was north-east direction, consistent with the direction of the fracture zone, with a clear gradient. According to remote sensing alteration information extraction, A3 and A4 both have a hydroxyl mineral abnormalities, and important indication of remote sensing mineralization and alteration. Therefore, aeromagnetic and remote sensing interpretation show that A3 and A4 have rich exception information, with good prospects of mineralization and can be used as clues for further exploration. 


\section{Conclusion}

By processing and analyzing the Lop Nur Pobei area 1: 50,000 high precision aeromagnetic data and landsat 8 remote sensing data, combined with regional metallogenic regularity and known mineral information, we analyse the aeromagnetic and remote sensing anomalies of the Pobei mafic - ultramafic rock mass comprehensively, and propose the important area for future exploration. The combining of aeromagnetic and remote sensing methods can provide more information on the target and improve the reliability of interpretation. The combining application of the two methods could improve the efficiency of prospecting.

\section{References}

[1] Xiong S Q. The present situation and development of airborne gravity and magnetic survey techniques in China[J], Progress in Geophy, 2009, 24(1): 113-117.

[2] Xiong S Q, Ding Y Y, Li Z Q etc.,Gravity and magnetic field characteristics and geological significance of Qiangtang Basin[J], Oil geophysical prospecting, 2013，48(6): 999-1010.

[3] Xiong S Q, Ding Y Y, Li Z Q etc.,Characteristics of Gravity and Magnetic Field in Xizang(Tibet) and New Understanding on Tectonic Framework in Eastern Xizang[J],Geological review, 2012, 58(2): $201-207$.

[4] Yang J M,Zhang Y J,Yao F J,etc., Dominant role of remote sensing mineral exploration information in the discovery of the Luodong Ni deposit,Xijiang[J], Acta petrologica sinica 2007 23(10): 2647-2652.

[5] Li HQ,Mei YP, Qu WJ,etc., SHRIMP zircon U-Pb and Re-Os dating of No.10 intrusive body and associated ores in Pobei maficultramafic belt of Xinjiang and its significance[J],Mineral deposits, 2009, 28(5): 633-642.

[6] Wang YL,Zhang ZW, Zhang MJ,etc., Geodynamic setting of the Pobei mafic-ultramafic intrusion in Xinjiang[J], Acta petrologica et mineralogical, 2013, 32(5): 693-707.

[7] Zhang XS,Fang HB, The tentative discussion on the mechanism of the interdependency between remote sensing technology and aeromagnetic technique and its application[J],Geophsical and Geochemical exploration, 2002, 26(1): 64-67.

[8] Zhang YJ, Yang JM, Chen W, A study of the method for extraction of alteration anomalies from the ETM+ (TM) data and its application: Geologic basis and spectral precondition[J],Remote sensing for land\&resources, 2002,(4):30-36.

[9] Yang JZ, Fang HB, Zhang YJ,etc., Remote sensing anomaly extraction in important metallogenic belts of western China[J], Remote sensing for land\&resources, 2003, (3):50-53. 